\title{
Влияние условий синтеза и наночастиц олова на структуру и свойства композитных тонких пленок $a-\mathrm{C}: \mathrm{H}\langle\mathrm{Sn}\rangle$
}

\author{
(C) А.П. Рягузов, Р.Р. Немкаева, Н.Р. Гусейнов \\ Национальная нанотехнологическая лаборатория открытого типа, \\ Казахский национальный университет им. аль-Фараби, \\ 050040 Алматы, Республика Казахстан \\ E-mail: ryaguzov_a@mail.ru
}

(Получена 5 декабря 2017 г. Принята к печати 29 января 2018 г.)

\begin{abstract}
Приводятся результаты исследования структуры и свойств композитных материалов на основе аморфных пленок $a$-С : Н и наночастиц олова. Синтез композитных пленок осуществлялся магнетронным ионноплазменным распылением комбинированной мишени в атмосфере смеси газов $92 \% \mathrm{Ar}: 4 \% \mathrm{CH}_{4}: 4 \% \mathrm{H}_{2}$. Методом комбинационного рассеяния света выявлена зависимость локальной структуры $a$-C : H $\langle\mathrm{Sn}\rangle$ пленок от условий синтеза и концентрации наночастиц олова. Показана зависимость интенсивности фотолюминесценции и значения оптической ширины запрещенной зоны в пленках $a-\mathrm{C}: \mathrm{H}\langle\mathrm{Sn}\rangle$ от концентрации $\mathrm{Sn}$.
\end{abstract}

DOI: 10.21883/FTP.2018.10.46463.8785

\section{1. Введение}

Разнообразие свойств кристаллических углеродных структур характеризуется определенным пространственным расположением C-C-связей и типом их гибридизации. В то же время немалый интерес вызывают структура и свойства аморфного углерода. Последние тридцать лет особое внимание уделяется изучению аморфных алмазоподобных углеродных пленок (DLC). Обладая особой прочностью и химической инертностью к агрессивным средам, аморфные DLC-пленки получили широкое применение в качестве антифрикционных и износостойких покрытий $[1,2]$ с высокими адгезионными свойствами.

На данный момент остается актуальным вопрос управления электронными процессами в аморфных гидрогенизированных углеродных пленках $(a-\mathrm{C}: \mathrm{H})$. Электронные процессы зависят от распределения плотности электронных состояний в зонах, которая определяется атомной структурой пленок $a-\mathrm{C}:$ Н. Как известно, формирование атомной структуры вещества зависит от многих факторов. При создании определенных структур в наноэлектронике требуется учитывать взаимодействия поверхности подложки с адатомами растущей пленки, в основе которых лежат электростатические силы [3]. Состояние и структура поверхности подложки существенно влияют на формирование пленки [4]. Кроме этого особую роль в формировании атомной структуры пленок играют термодинамические условия синтеза [5]. Применяя магнетронный ионно-плазменный метод синтеза, возможно в широких пределах термодинамических параметров осуществить структурно-примесную модификацию пленок $a-\mathrm{C}: \mathrm{H}$ и таким образом управлять их электронными свойствами.

Углерод - один из немногих элементов, который не образует химической связи в широком интервале условий синтеза с достаточно большим количеством веществ. Это свойство позволяет формировать в угле- родной матрице наночастицы. Углеродные пленки, модифицированные наночастицами некарбидообразующего вещества, составляют определенный класс композитов с уникальными свойствами. Благодаря квантовым размерным эффектам в наночастицах могут проявляться новые свойства, существенно отличающиеся от свойств этих материалов с размерами > 100 нм. Например, наночастицы серебра, золота и платины в углеродной матрице проявляют плазмонный резонанс поглощения и перколяционный механизм проводимости [6-9], в основе которых квантовые состояния электронной подструктуры наночастиц. Композитные материалы широко исследуются и находят все бо́льшую область применения [10-14]. Возможность управления электронными процессами в композитных материалах на основе аморфных углеродных пленок позволит расширить область их использования, в частности для создания высокочувствительных сенсоров, новых устройств в нано-, оптоэлектронике и др.

В данной работе для модификации углеродных пленок было выбрано олово, которое относится к некарбидообразующим элементам и может существовать в двух модификациях: $\alpha$-Sn - серое олово, с атомной структурой алмаза, относится к полупроводникам; $\beta-\mathrm{Sn}$ - белое олово, пластичный металл с тетрагональной атомной структурой. В зависимости от условий синтеза, концентрации и размеров наночастиц олова может происходить его формирование в $\alpha$ - или $\beta$-модификации структуры. Поэтому наночастицы олова будут по-разному влиять на формирование структуры углеродной матрицы и на ее электронные свойства.

В работе показаны результаты по изучению структуры и свойств синтезируемых пленок в зависимости от условий синтеза и концентрации олова. На основе представлений о $s p^{2}-$ и $s p^{3}$-гибридизации $\mathrm{C}-\mathrm{C}$-связей углеродной матрицы, об $\alpha$ - и $\beta$-модификациях наночастиц олова предложено объяснение люминесцентных и оптических свойств пленок $a-\mathrm{C}: \mathrm{H}\langle\mathrm{Sn}\rangle$. 

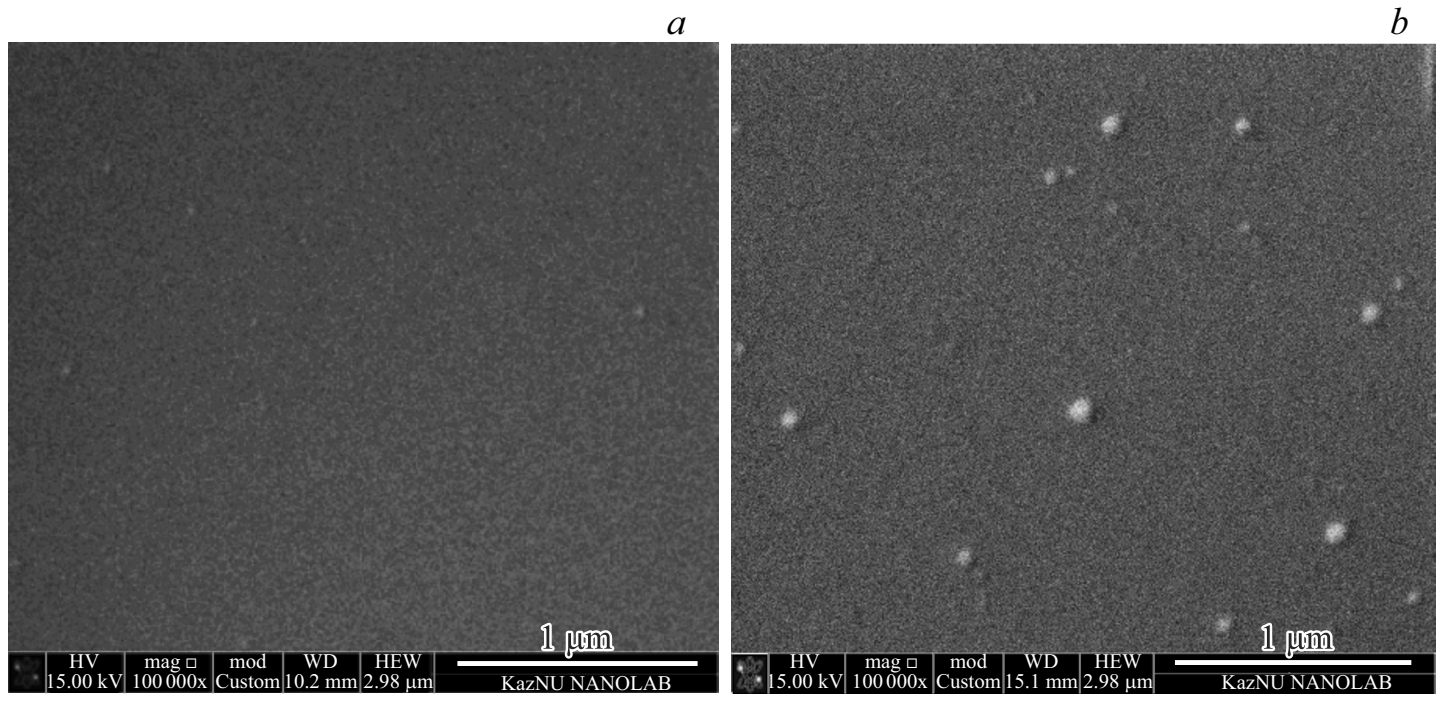

Рис. 1. Электронная микроскопия поверхности пленок $a-\mathrm{C}: \mathrm{H}\left\langle\mathrm{Sn}_{x}\right\rangle . X_{\mathrm{Sn}}$, aт\%. $a-0, b-3.18$.

\section{2. Методы синтеза и исследования структуры и свойств}

Методом магнетронного ионно-плазменного распыления комбинированной мишени в атмосфере смеси газов $92 \% \mathrm{Ar}: 4 \% \mathrm{CH}_{4}: 4 \% \mathrm{H}_{2}$ на постоянном токе (DC) синтезированы композитные пленки $a-\mathrm{C}: \mathrm{H}\left\langle\mathrm{Sn}_{x}\right\rangle$. Магнитное поле магнетрона создавалось с использованием электромагнита на постоянном токе. Корректировка величины магнитного поля позволяла поддерживать постоянными значения напряжения и тока плазмы разряда в процессе синтеза пленок. Чистота газов и графитовой мишени составляла $99.999 \%$, олова - 99.98\%. Пленки $a-\mathrm{C}: \mathrm{H}\left\langle\mathrm{Sn}_{x}\right\rangle$ синтезированы при давлении 0.7 Па и температурах подложки $T_{\mathrm{sub}}=50$ и $250^{\circ} \mathrm{C}$. Удельная мощность DC ионно-плазменного разряда имело значение $P_{d}=2.5 \mathrm{~B} / \mathrm{cm}^{2}$. Синтез пленок осуществлялся одновременно на кремниевых, $\mathrm{Si}(100)$, и кварцевых, $\mathrm{SiO}_{2}$, пластинах. Средняя скорость роста пленок была $\sim 0.2 \AA /$ c. Толщина пленок составляла $(60 \pm 10)$ нм в зависимости от условий синтеза. Отметим, что при температуре подложки $T_{\text {sub }}=250^{\circ} \mathrm{C}$ в процессе роста пленки, помимо распыления мишени ионами аргона активно принимает участие термически активированная хемосорбция, вызванная разложением молекул метана.

Толщина и структура поверхности синтезируемых пленок изучались в сканирующем электронном микроскопе (СЭМ) (Quanta 200i 3D, FEI Company). Методом комбинационного рассеяния света (КРС) проводились исследования структуры синтезируемых пленок в зависимости от условий синтеза на установке NTegra Spectra (НТ-МДТ, Россия) с использованием лазера с длиной волны излучения $\lambda=473$ нм. Концентрация олова $X_{\mathrm{Sn}}$ определялась методом энергодисперсионного рентгеновского микроанализа (EDS) с точностью \pm 0.01 ат.\%. Оптические спектры пропускания и отражения изучались на спектрофотометре UV-3600 (Shimadzu, Япония).

\section{3. Результаты и их обсуждение}

Исследования структуры поверхности синтезированных пленок $a$-C: $\mathrm{H}\left\langle\mathrm{Sn}_{x}\right\rangle$ в СЭМ показали, что олово формирует наночастицы сферической формы с размерами от 10 до 80 нм и в зависимости от концентрации их количество на единице площади различается. На рис. 1 приведены снимки чистой пленки и пленки с примесью олова, которые были синтезированы при $2.5 \mathrm{BT} / \mathrm{cm}^{2}$ и $T_{\text {sub }}=50^{\circ} \mathrm{C}$ на кремниевых подложках. На рис. 2 приведены спектры $\mathrm{EDS}$ для чистой пленки $a$-C : Н и пленки с примесью олова, $a-\mathrm{C}: \mathrm{H}\left\langle\mathrm{Sn}_{x}\right\rangle$, синтезированных на $\mathrm{Si}$.

Методом КРС выявлено различие в локальной структуре $a-\mathrm{C}: \mathrm{H}$ и пленок $a-\mathrm{C}: \mathrm{H}\left\langle\mathrm{Sn}_{x}\right\rangle$, синтезированных на пластинах $\mathrm{Si}(100)$ и $\mathrm{SiO}_{2}$. Как известно $[15,16]$, спектры КРС углеродных структур характеризуются двумя основными пиками - пик $G$ в области частот от 1500 до $1600 \mathrm{~cm}^{-1}$ и пик $D$ в диапазоне $1350-1450 \mathrm{~cm}^{-1}$. На рис. 3 приведены спектры КРС пленок $a$-С:Н и $a-\mathrm{C}: \mathrm{H}\left\langle\mathrm{Sn}_{x}\right\rangle$, откуда видно влияние концентрации олова на формирование локальной структуры углеродной матрицы. Более подробно влияние термодинамических и кинетических условий синтеза на свойства пленок $a$-С и $a-\mathrm{C}: \mathrm{H}$ нами рассмотрено в работах $[4,17]$.

Увеличение концентрации олова приводит к смещению $G$-пика в высокочастотную область и к увеличению наклона спектра КРС, что обусловлено увеличением интенсивности фотолюминесценции (ФЛ). Смещение $G$-пика в высокочастотную область указывает на увеличение количества $s p^{2}$-узлов в аморфной пленке $a$-C : $\mathrm{H}\left\langle\mathrm{Sn}_{x}\right\rangle$, т. е. графитизацию ее структуры. Сравнивая рис. 3, $a$ и $b$, можно видеть, что в пленках на кварцевых подложках $G$-пик при равных концентрациях олова смещен в высокочастотную область на $5 \mathrm{~cm}^{-1}$. Такое смещение указывает на разницу в концентрации $s p^{2}$-узлов, но при этом наклон кривой КРС в пленках $a$-C: $\mathrm{H}\left\langle\mathrm{Sn}_{x}\right\rangle$, 

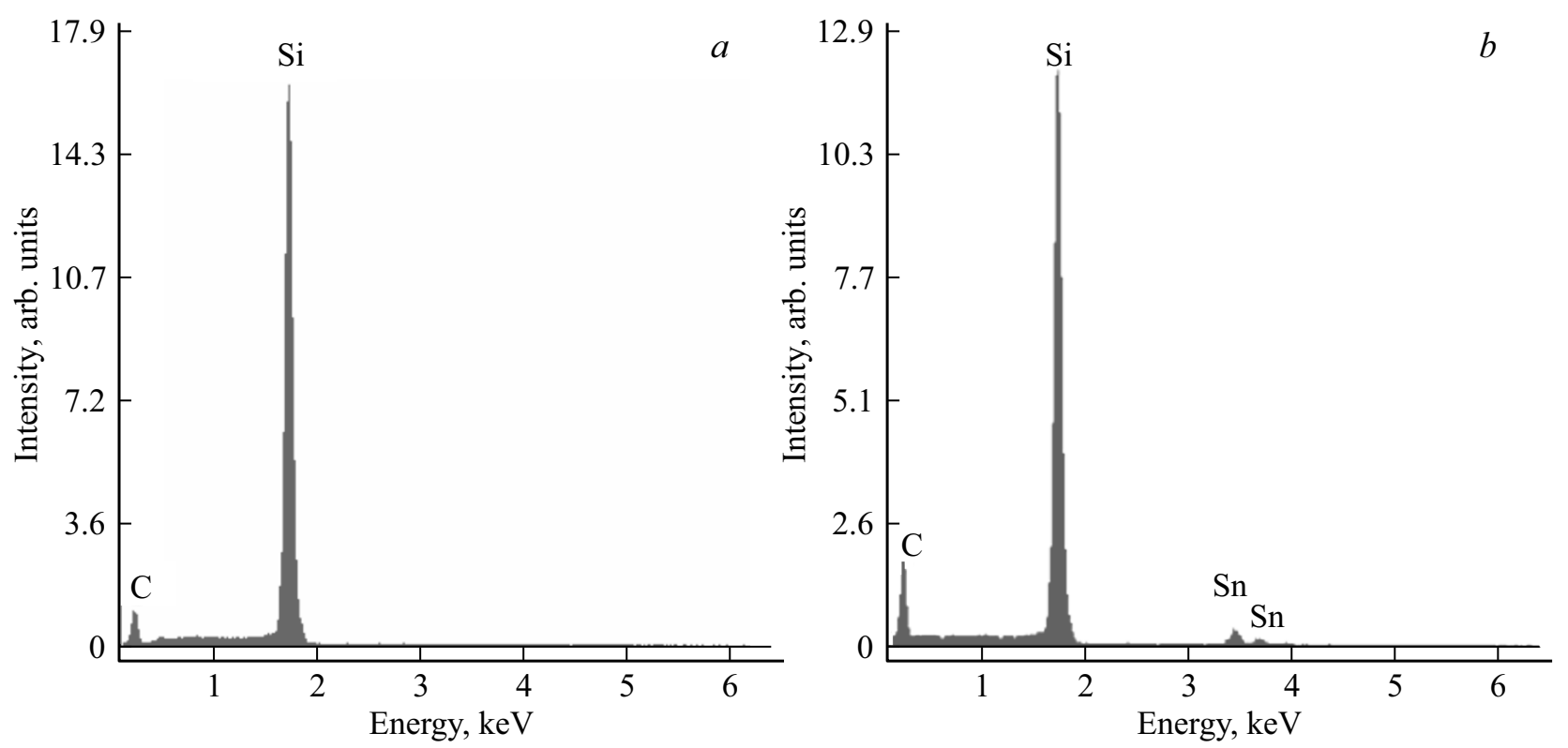

Рис. 2. Спектры EDS пленок $a-\mathrm{C}: \mathrm{H}\left\langle\mathrm{Sn}_{x}\right\rangle . X_{\mathrm{Sn}}, \mathrm{aT} \%: a-0, b-3.18$.

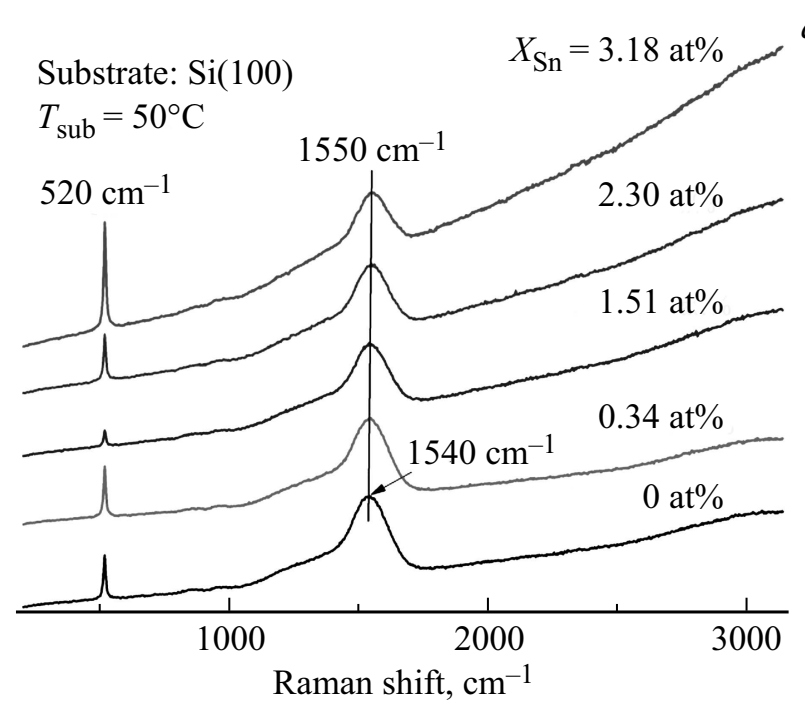

\section{$a$}

Substrate: $\mathrm{SiO}_{2}$

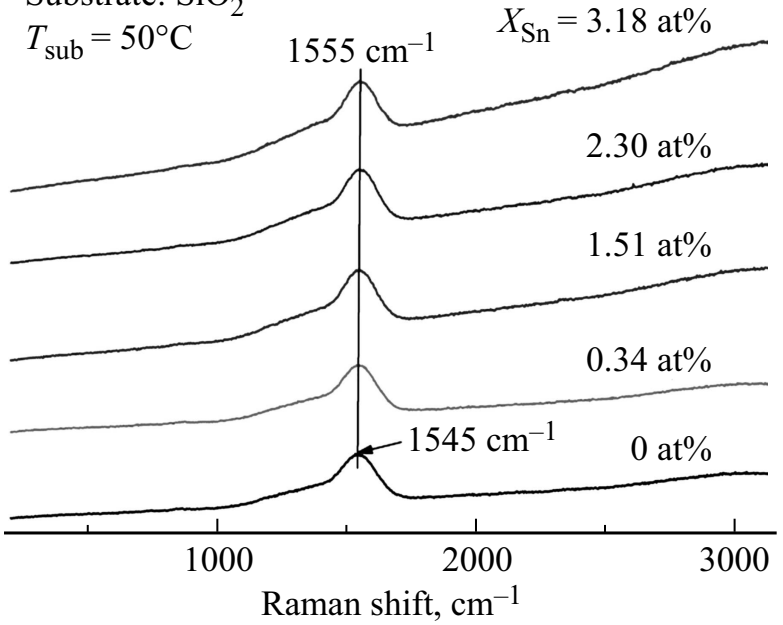

Рис. 3. Спектры КРС пленок $a$-C : $\mathrm{H}\left\langle\mathrm{Sn}_{x}\right\rangle$, синтезированных на кремниевых $(a)$ и кварцевых $(b)$ подложках.

синтезированных на подложках $\mathrm{SiO}_{2}$, меньше, чем на подложках $\mathrm{Si}(100)$. Отличие в угле наклона фона ФЛ можно объяснить существующей разницей в интенсивностях излучения. Число излучательных переходов зависит от распределения плотности локализованных состояний в зонах, что в свою очередь обусловлено атомной структурой пленки. Формирование атомной структуры пленок $a$-C : $\mathrm{H}\left\langle\mathrm{Sn}_{x}\right\rangle$ при данных условиях синтеза зависит от распределения поверхностного потенциала подложки и кроме этого, как видно из рис. 3, от концентрации олова. Кристаллическая поверхность кремния (100) способствует формированию $s p^{3}$-узлов, что определяется смещением $G$-пика в низкочастотную область.
Другим важным параметром, влияющим на формирование структуры пленок $a-\mathrm{C}: \mathrm{H}\left\langle\mathrm{Sn}_{x}\right\rangle$, является температура подложки. Зависимости спектров КРС пленок $a-\mathrm{C}: \mathrm{H}\left\langle\mathrm{Sn}_{x}\right\rangle$ на разных подложках от температуры приведены на рис. 4. Можно видеть, что увеличение $T_{\text {sub }}$ приводит к существенному смещению $G$-пика в высокочастотную область, на $30 \mathrm{~cm}^{-1}$, что указывает на увеличение количества $s p^{2}$-узлов. Положение $G$-пика в пленках, синтезированных при $250^{\circ} \mathrm{C}$, соответствует $1575 \mathrm{~cm}^{-1}$ в случае пленок на кремниевых подложках и $1580 \mathrm{~cm}^{-1}$ на кварцевых подложках. Данные частоты излучения в спектрах КРС характерны для высокоориентированного пиролитического графита и поликристаллического графита $[15,18]$. В кристаллах ширина на по- 


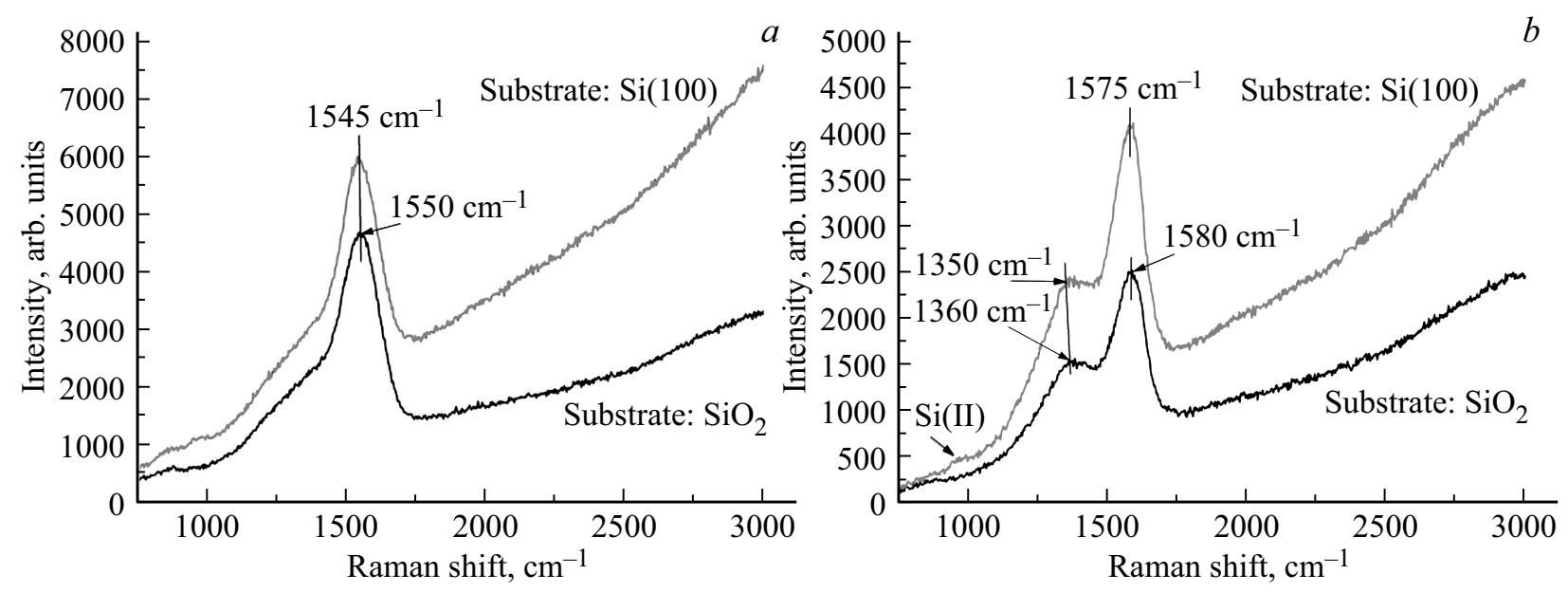

Рис. 4. Спектры КРС в пленках $a$-C : $\mathrm{H}\left\langle\mathrm{Sn}_{x}\right\rangle$, синтезированных при температурах подложки $50 \quad(a)$, $250^{\circ} \mathrm{C}(b)$. $X_{\mathrm{Sn}}=(1.5 \pm 0.2) \mathrm{aT} \%, P_{d}=2.5 \mathrm{BT} / \mathrm{cm}^{2}$.

лувысоте $G$-пика $\left(\mathrm{FWHM}_{G}\right)$ составляет $\sim(10-30) \mathrm{cm}^{-1}$, что указывает на упорядоченность атомной структуры [19]. На рис. 4 при $T_{\text {sub }}=50$ и $250^{\circ} \mathrm{C} \mathrm{FWHM}_{G}$ составляет $\sim 180$ и $\sim 150 \mathrm{~cm}^{-1}$ соответственно. Значения $\mathrm{FWHM}_{G}$ в пленках $a-\mathrm{C}: \mathrm{H}\left\langle\mathrm{Sn}_{x}\right\rangle$ существенно больше, чем в кристаллах [19], что характеризует высокую степень разупорядоченности атомной структуры. Появление $D$-пика связано с дыхательной модой гексагональной молекулы $\mathrm{C}_{6}$, и это возможно только при появлении 2 или 3 степеней свободы. Поэтому появление дыхательной моды у $\mathrm{C}_{6}$ возможно в неупорядоченной атомной структуре. В пленках $a-\mathrm{C}: \mathrm{H}\left\langle\mathrm{Sn}_{x}\right\rangle$, синтезированных при $250^{\circ} \mathrm{C}$, пик $D$ более явно выражен, что соответствует большему процентному содержанию кристаллических кластеров графита в аморфной углеродной матрице по сравнению с пленками, синтезированными при $50^{\circ} \mathrm{C}$.

Проведены исследования локальной структуры пленок $a-\mathrm{C}: \mathrm{H}\left\langle\mathrm{Sn}_{x}\right\rangle$, синтезированных при температуре $250^{\circ} \mathrm{C}$. При данной температуре синтеза наночастицы олова никак не повлияли на изменение формы спектра КРС и положение максимума $G$-пика, т.е. при температуре синтеза $250^{\circ} \mathrm{C}$ влияние наночастиц олова на формирование атомной структуры аморфной углеродной матрицы подавлено. Кроме этого, можно заметить влияние материала и структуры подложки на формирование пленки, проявляющееся в отличии наклона спектра КРС, связанном с изменением интенсивности ФЛ. Кристаллическая фаза кремниевой подложки, как было отмечено выше, способствует в большей степени образованию $s p^{3}$-гибридизованных связей. Уменьшается количество $\boldsymbol{\pi}$-электронов и соответственно плотность локализованных состояний внутри запрещенной зоны в отличие от распределения электронной плотности в пленках, синтезированных на кварцевых подложках. Уменьшение плотности локализованных состояний внутри запрещенной зоны приводит к уменьшению вероятности процессов термализации и соответственно увеличивает количество излучательных переходов.
Подобное изменение спектров комбинационного рассеяния света наблюдается для пленок, синтезированных при удельной мощности ионно-плазменного разряда в интервале от 2.0 до $3.0 \mathrm{BT} / \mathrm{cm}^{2}$ и концентрации олова до $3.5 \mathrm{aT} \%$ [20]. Нужно отметить, что если положение максимума $G$-пика $1550 \mathrm{~cm}^{-1}$ и меньше, то пленки $a-\mathrm{C}: \mathrm{H}\left\langle\mathrm{Sn}_{x}\right\rangle$ содержат от 40 до 70\% $s p^{3}$-узлов в атомной структуре. Однако это утверждение справедливо для пленок с оптической шириной запрещенной зоны в интервале от 1.0 до 1.8 эВ соответственно [19]. Только в этом случае возможно формирование аморфной алмазоподобной углеродной матрицы с высокими коэффициентом твердости и пределом прочности [19].

Изменение наклона спектра КРС и положение максимума $G$-пика могут быть обусловлены не только влиянием материала подложки и условиями синтеза, но и влиянием поверхностного потенциала наночастицы олова на формирование атомной структуры пленки. Это подтверждает зависимость ФЛ от концентрации олова в пленках $a-\mathrm{C}: \mathrm{H}\left\langle\mathrm{Sn}_{x}\right\rangle$, синтезированных при удельной мощности плазменного разряда $2.5 \mathrm{~B} / \mathrm{cm}^{2}$ (рис. 5 ).

Как видно из рис. 5, интенсивность ФЛ увеличивается с ростом концентрации олова. Согласно результатам работы [21], ФЛ в пленках $a-\mathrm{C}: \mathrm{H}\left\langle\mathrm{Sn}_{x}\right\rangle$, синтезированных на кварцевых подложках при $P_{d}=2.0 \mathrm{BT} / \mathrm{cm}^{2}$, достигает максимума при концентрации олова $\sim 3.0$ ат\%. Дальнейшее увеличение приводит к уменьшению фотолюминесценции. Такое поведение в изменении интенсивности ФЛ в работе [21] связывают с изменением ширины запрещенной зоны и ее зависимости от концентрации олова. Концентрация олова определяет диаметр наночастиц. Размер наночастиц $\mathrm{Sn}$ определяет его модификацию $-\alpha$-Sn или $\beta$-Sn, что влияет на формирование $s p^{3}$ - и $s p^{2}$-узлов С-С. В свою очередь, соотношение $s p^{2} / s p^{3}$ влияет на формирование плотности состояний в зоне. Увеличение или уменьшение количества $s p^{2}$-узлов приводит к изменению количества $\pi$ - и $\pi^{*}$-состояний электронов, которые обусловливают формирование локализованных состояний в запрещенной зоне и хвостах 


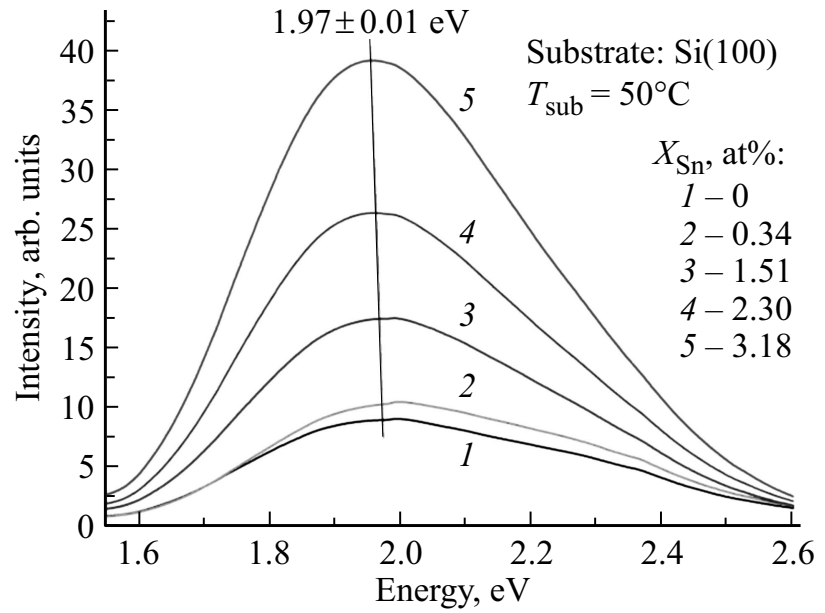

Рис. 5. Спектры ФЛ пленок $a-\mathrm{C}: \mathrm{H}\left\langle\mathrm{Sn}_{x}\right\rangle$, синтезированных ионно-плазменным методом на постоянном токе при $P_{d}=2.5 \mathrm{BT} / \mathrm{cm}^{2}$.

краев зон. Кроме этого, энергетическое распределение плотности электронных состояний наночастиц олова также вносит существенный вклад в формирование краев энергетических зон и внутризонных электронных переходов.

В работе [21] положение максимума интенсивности фотолюминесценции в пленках $a$-C : $\mathrm{H}\left\langle\mathrm{Sn}_{x}\right\rangle$ соответствует $\sim 2.02$ эВ и не зависит от концентрации олова. Как видно из рис. 5, в случае пленок, синтезированных при $P_{d}=2.5 \mathrm{BT} / \mathrm{cm}^{2}$ на пластине $\mathrm{Si}(100)$, максимум интенсивности ФЛ сместился в низкоэнергетическую область и его положение изменяется с изменением концентрации олова. Такое влияние наночастиц олова на ФЛ определяет изменение соотношения узлов $s p^{2} / s p^{3}$. За ФЛ отвечает определенная конфигурация узлов $s p^{2}$ и $s p^{3}$, формирующая излучательный электронный переход в запрещенной зоне с энергией в интервале от 1.96 до 2.02 эВ.

Уменьшение интенсивности ФЛ в [21] мы связываем с увеличением количества наночастиц олова в металлической модификации $\beta$-Sn. Модификация $\beta-\mathrm{Sn}$, повидимому, приводит к увеличению числа $s p^{2}$-узлов, что в свою очередь увеличивает плотность $\pi$-электронных состояний внутри запрещенной зоны. Возникновение дополнительных состояний в зоне обусловливает увеличение вероятности термических переходов, что и приводит к уменьшению интенсивности ФЛ. Кроме этого, нужно отметить, что наночастицы металлического олова могут дополнительно создавать локализацию разрешенных состояний вблизи потолка валентной зоны - примесный центр, который может быть причиной увеличения числа излучательных переходов. Увеличение концентрации $\mathrm{Sn}$ более 3.0 ат\% [21] приводит к возможному уширению энергетической полосы состояний ниже уровня Ферми, что и приводит к увеличению вероятности термических переходов и, как следствие, к уменьшению интенсивности ФЛ. Таким образом, в процессе ФЛ могут участвовать как $\pi$-электроны $s p^{2}$-узлов, так и электроны наночастиц модификации $\beta$-Sn.

Структурно-чувствительным параметром, характеризующим электронные переходы, является оптическая ширина запрещенной зоны $\left(E_{g}\right)$. Поэтому исследование влияния наночастиц олова на величину энергетической щели пленок $a$-С : Н может дать дополнительную информацию о формировании электронной плотности состояний вблизи краев зон. В аморфных полупроводниках добавление примеси в небольших концентрациях не влияет на величину запрещенной зоны, а с увеличением концентрации приводит к ее уменьшению [22-26]. Олово не образует химической связи с атомом углерода, и поэтому наночастицы олова не могут непосредственно участвовать в формировании распределения электронных состояний в зонах.

В данной работе $E_{g}$ синтезированных пленок была определена по закону Тауца $\alpha h v \propto\left(h v-E_{g}\right)^{2}$ в области края фундаментального поглощения при коэффициенте поглощения $\alpha \sim 10^{5} \mathrm{~cm}^{-1}$ и оптической плотности $\alpha d \sim 1$. В пленке $a-\mathrm{C}: \mathrm{H}$ ширина запрещенной зоны при $P_{d}=2.5 \mathrm{BT} / \mathrm{cm}^{2}$ составляет $\sim 1.26$ эВ. Добавление олова до концентрации $\sim 1 \mathrm{aT} \%$ увеличивает $E_{g}$, а при дальнейшем увеличении концентрации Sn наблюдается плавное уменьшение ширины запрещенной зоны. Подобная картина изменения $E_{g}$ в зависимости от $X_{\mathrm{Sn}}$ наблюдается в пленках, синтезированных при температуре $T_{\text {sub }}=250^{\circ} \mathrm{C}$.

Наночастицы олова неоднозначно влияют на формирование краев разрешенных зон, что приводит к нескольким механизмам формирования электронной плотности состояний. При концентрациях $<1$ ат\% диаметр наночастиц $\alpha$-Sn не превышает 10 нм и поэтому количество атомов олова на частицу составляет в среднем $\sim 28000$. При таком количестве атомов ширина запрещенной зоны наночастицы модификации $\alpha$-Sn увеличивается, что может стать причиной перераспределения электронов между наночастицей и углеродной матрицей и изменения $E_{g}$ в пленке $a-\mathrm{C}: \mathrm{H}\left\langle\mathrm{Sn}_{x}\right\rangle$.

Предполагается, что наночастицы олова способны формировать дополнительную плотность разрешенных состояний выше края валентной зоны и таким образом влиять на плотность $\pi$-электронов, которые формируют край валентной зоны в углеродной матрице. Увеличение концентрации олова приводит к увеличению размеров наночастиц, что способствует переходу их атомной структуры в $\beta$-модификацию и соответственно изменению энергетического состояния электронов. В этом случае наночастицы играют роль примесных центров. Помимо этого структурные изменения наночастиц олова могут существенно влиять на формирование углеродной матрицы и содержание $s p^{2}$-узлов. Это может привести к изменению распределения электронной плотности состояний и уменьшению ширины запрещенной зоны.

\section{4. Заключение}

В работе рассмотрено влияние наночастиц олова и температуры синтеза на структуру и электронные свой- 
ства композитных пленок $a-\mathrm{C}: \mathrm{H}\left\langle\mathrm{Sn}_{x}\right\rangle$. Показано существенное влияние температуры и материала подложки на формирование структуры пленок. Изменение структуры связано с изменением соотношения $s p^{2}-/ s p^{3}$-гибридизованных связей. Формирование аморфной углеродной матрицы зависит от концентрации, размеров и структурной модификации наночастиц олова. Олово не образует химической связи с атомами углерода, но при этом энергетический спектр состояний наночастицы олова влияет на плотность электронных состояний, формируемую $\pi$-электронами углеродной матрицы. Это влияние приводит к изменению электронных свойств пленки $a$-C : $\mathrm{H}\left\langle\mathrm{Sn}_{x}\right\rangle$. Показано, что фотолюминесценция существенно зависит от концентрации олова. При введении $\mathrm{Sn}$ до $3 \mathrm{aT \%}$ ФЛ увеличивается более чем в 5 раз. Необычные оптические свойства проявляются в области концентраций до 1.5 ат\%. Олово в зависимости от размеров наночастиц может формироваться в двух различных модификациях атомной структуры: $\alpha-$ модификация олова с полупроводниковыми свойствами, $\beta$ - модификация олова с металлическими свойствами; они по-разному влияют на формирование электронной плотности состояний краев зон и плотности внутризонных состояний. Проведенные исследования открывают дополнительную возможность модификации свойств аморфных углеродных пленок и создания композитных материалов с новыми электронными свойствами.

Работа выполнена в рамках грантового финансирования 3219/ГФ комитета науки МОН Республики Казахстан.

\section{Список литературы}

[1] A. Erdemir, Ch. Donnet. J. Phys. D: Appl. Phys., 39, R311 (2006).

[2] M. Suzuki, T. Ohana, A. Tanaka. Diamond Relat. Mater., 13 (11-12), 2216 (2004).

[3] Р.А. Андриевский. Успехи химии, 66 (1), 57 (1997).

[4] A.P. Ryaguzov, G.A. Yermekov, R.R. Nemkayeva, N.R. Guseinov, R.K. Aliaskarov. J. Mater. Res., 31 (1), 127 (2016).

[5] А.Д. Коротаев, С.В. Овчинников, А.Н. Тюменцев, Ю.П. Пинжин, Г.Ю. Юшков, А.Г. Николаев, К.П. Савкин. Поверхность. Рентген., синхротрон. и нейтр. исслед., № 1 , 46 (2004).

[6] Š. Meškinis, A. Čiegis, A. Vasiliauskas, K. Šlapikas, T. Tamulevičius, A. Tamulevičienè, S. Tamulevičius. Thin Sol. Films, 581, 48 (2014).

[7] Ye.J. Jo, T.F. Zhang, M.J. Son, K.H. Kim. Appl. Surf. Sci., 433, 1184 (2018).

[8] B.F. Dorfman. Thin Sol. Films, 330 (2), 76 (1998).

[9] Sh.Sh. Sarsembinov, O.Yu. Prikhodko, A.P. Ryaguzov, S.Ya. Maksimova, Ye.A. Daineko, F.A. Mahmoud. Physica Status Solidi C, 7 (3-4), 805 (2010).

[10] T. Acsente, E.R. Ionita, D. Colceag, A. Moldovan, C. Luculescu, R. Birjega, G. Dinescu. Thin Sol. Films, 519, 4054 (2011).

[11] A. Chandrashekar, S. Ramachandran, G. Pollack, J.S. Lee, G.S. Lee, L. Overzet. Thin Sol. Films, 517, 525 (2008).
[12] X.M. Dong, Y. Luo, L.N. Xie, R.W. Fu, M.Q. Zhang. Thin Sol. Films, 516, 7886 (2008).

[13] G. Yar-Mukhamedova, G. Ismailova, A. Markhabaeva, A. Darisheva. Asian J. Natural \& Appl. Sci., 3 (1), 61 (2014).

[14] F.F. Komarov, G.A. Ismailova, O.V. Mil'chanin, I.N. Parkhomenko, F.B. Zhusipbekova, G.Sh. Yar-Mukhamedova. Technical Physics, 60 (9), 1348 (2015).

[15] A.C. Ferrari, J. Robertson. Phys. Rev. B, 61 (20), 14095 (2000).

[16] D.S. Knight, W.B. White. J. Mater. Res., 4 (2), 385 (1989).

[17] A.P. Ryaguzov, B.E. Alpysbayeva, R.R. Nemkayeva, R.K. Aliaskarov, D.M. Mamyrbayeva, O.I. Yukhnovets. Eur. Phys. Tech. J., 13 (1), 52 (2016).

[18] F. Tuinstra, J.L. Koening. J. Chem. Phys., 53, 1126 (1970).

[19] A.C. Ferrari, J. Robertson. Philos. Trans. Royal Soc., 362 (1824), 2477 (2004).

[20] А.П. Рягузов, Р.Р. Немкаева, Н.Р. Гусейнов, Д.М. Мамырбаева. В сб.: Современные технологии в науке $u$ образовании СТНО-2017, под ред. О.В. Миловзорова (Рязань, Рязан. гос. радиотехн. ун-т, 2017) с. 191.

[21] А.П. Рягузов, Р.Р. Немкаева, Н.Р. Гусейнов, Д.М. Мамырбаева. В сб.: Современные технологии в науке $и$ образовании СТНО-2017, под ред. О.В. Миловзорова (Рязань, Рязан. гос. радиотехн. ун-т, 2017) с. 182.

[22] A. Marchenko, N. Anisimova, A. Naletko, T. Rabchanova, P. Seregin, H. Ali. Glass Phys. Chem., 39 (3), 287 (2013).

[23] S. Coffa, S. Lombardo, F. Priolo, G. Franzó, S.U. Campisano, A. Polman, G.N. van den Hoven. Il Nuovo Cimento D, 18 (10), 1131 (1996).

[24] P. Brogueira, V. Chu, A.C. Ferro, J.P. Conde. J. Vacuum Sci. Technol. A: Vacuum, Surfaces, Films, 15 (6), 2968 (1997).

[25] S. Meskinis, R. Gudaitis, A. Vasiliauskas, A. Ciegis, K. Slapikas, T. Tamulevicius, M. Andrulevicius, S. Tamulevicius. Diamond Relat. Mater., 60, 20 (2005).

[26] D.I. Jones, A.D. Stewart. Phil. Mag. B, 46 (5), 423 (1982).

Редактор Л.В. Шаронова

\section{Effect of synthesis conditions and tin nanoparticles on structure and properties of $a-\mathbf{C}: \mathbf{H}\langle\mathbf{S n}\rangle$ composite thin films}

\author{
A.P. Ryaguzov, R.R. Nemkayeva, N.R. Guseinov
}

National Nanotechnological Laboratory of Open Type, al-Farabi KazNU,

050040 Almaty, Republic of Kazakhstan

Abstract Studies of the structure and properties of composite materials based on amorphous $a-\mathrm{C}: \mathrm{H}$ films and tin nanoparticles are reported. Synthesis of the composite films was conducted using magnetron ion-plasma sputtering of a combined target in atmosphere of the gas mixture $92 \% \mathrm{Ar}: 4 \% \mathrm{CH}_{4}: 4 \% \mathrm{H}_{2}$. Using Raman spectroscopy the dependence of local structure of the $a-\mathrm{C}: \mathrm{H}\langle\mathrm{Sn}\rangle$ films on synthesis conditions and concentration of tin nanoparticles was revealed. The dependence of photoluminescence intensity and value of optical bandgap in $a-\mathrm{C}: \mathrm{H}\langle\mathrm{Sn}\rangle$ films on $\mathrm{Sn}$ concentration is shown. 